УДК 548.736 .4

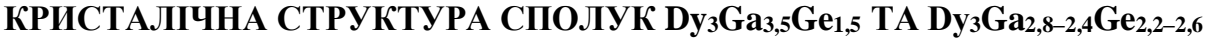

\section{Т. Деленко*, Я. Токайчук, Р. Гладишевський}

\author{
Львівський національний університет імені Івана Франка, \\ вул. Кирила і Мефодія, 6, 79005 Львів, Україна \\ e-mail: tarasdelenko@gmail.com
}

\begin{abstract}
Синтезовано та методами рентгеноспектрального і рентгеноструктурного аналізів визначено склад i кристалічну структуру двох нових тернарних сполук: Dy3 $\mathrm{Ga}_{3,5} \mathrm{Ge}_{1,5}$ (структурний тип $\mathrm{Tm}_{3} \mathrm{Ga} 5$; символ Пірсона $о P 32$; просторова група Pnтa; $a=11,6672(11)$, $b=9,4411(8), c=6,0267(5) \AA)$ i $\mathrm{Dy}_{3} \mathrm{Ga}_{2,8-2,4} \mathrm{Ge}_{2,2-2,6}\left(\mathrm{Pu}_{3} \mathrm{Pd}_{5} ; o S 32 ; C m c m ; a=9,3738(11)\right.$ 9,3599(11), $b=7,4816(8)-7,4788(9), c=9,4068(11)-9,4148(12) \AA ̊)$. Структурні типи $\mathrm{Tm}_{3} \mathrm{Ga}_{5}$ та $\mathrm{Pu}_{3} \mathrm{Pd}$ 5 належать до родини деформованих похідних структури типу $\mathrm{Rh}_{5} \mathrm{Ge}_{3}$, що характеризується взаємноз'єднаними колонами заповнених тригональних призм, що утворюють каркас 3 великими гексагональними каналами. В структурах синтезованих сполук можна також виділити тетрагонально-пірамідальні кластери з атомів $\mathrm{Ga}$ i Ge.
\end{abstract}

Ключові слова: диспрозій, галій, германій, рентгенівський дифракційний метод порошку, кристалічна структура.

DOI: https://doi.org/10.30970/vch.6001.091

\section{1. Вступ}

Системи $R-\mathrm{Ga}-\mathrm{Ge}(R-$ рідкісноземельний метал) $є$ багатими на тернарні сполуки: сьогодні відомо про існування 63 тернарних галідо-германідів, кристалічні структури яких належать до 40 структурних типів [1]. У системі 3 Dу досі повідомлено про існування п'яти тернарних сполук 3 вмістом 22,2-33,3 ат. \% Dy: $\mathrm{Dy}_{2} \mathrm{Ga}_{1,8} \mathrm{Ge}_{5,2}$ (структурний тип (CT) $\mathrm{Sm}_{2}\left(\mathrm{Ga}_{0,26} \mathrm{Ge}_{0,74}\right)_{7}$; символ Пірсона (CП) $o S 80,64$; просторова група (ПГ) Cmce; $a=8,3284, b=8,0320, c=20,9167 \AA$ ) [2], $\mathrm{DyGa}_{2,92-2,52} \mathrm{Ge}_{0,08-0,48}\left(\mathrm{CT} \mathrm{Mg} \mathrm{Mg}_{3} \mathrm{In}\right.$; CП $h R 48$; ПГ $R-3 m ; a=6,1707-6,22374, c=27,7297-$ $28,1185 \AA)$ [3], $\mathrm{DyGa}_{2,32-2,20} \mathrm{Ge}_{0,68-0,80}\left(\mathrm{CT} \mathrm{PuAl}_{3} ; \mathrm{C \Pi} h P 24 ; \Pi \Gamma P 6_{3} / m m c ; a=6,0970\right.$ 6,1091, $c=14,3153-14,3528 \AA)$ [3], DyGa ${ }_{1,4} \mathrm{Ge}_{0,6}\left(\mathrm{CT} \alpha-\mathrm{ThSi}_{2} ;\right.$ CП $t$ I12; ПГ I4 $/$ /amd; $a=4,16411, c=14,4832 \AA)$ [4] та $\mathrm{DyGa}_{0,15} \mathrm{Ge}_{1,85}\left(\mathrm{CT} \mathrm{PrGe}_{1,91} ; \mathrm{C \Pi} o S 24 ;\right.$ ПГ Cmmm; $a=4,102, b=29,896, c=3,339 \AA$ ) [5]. Однак у системах 3 деякими іншими рідкісноземельними металами існують тернарні сполуки і 3 більшим вмістом $R$. Зокрема, у системі Er-Ga-Ge на ізоконцентраті 37,5 ат. \% Er існує дві тернарні фази: $\mathrm{Er}_{3} \mathrm{Ga}_{2,7} \mathrm{Ge}_{2,3}\left(\mathrm{CT} \mathrm{Tm} \mathrm{Ga}_{5}\right.$; СП oP32; ПГ Pnma; $a=11,573, b=9,368, c=5,958 \AA$ ) [6] та $\mathrm{Er}_{3} \mathrm{Ga}_{2,21-2,15} \mathrm{Ge}_{2,79-2,85}\left(\mathrm{CT} \mathrm{Pu} \mathrm{Pd}_{5}\right.$; СП $o S 32 ;$ ПГ Cmcm; $a=9,2880-9,269, b=7,4180$ 7,402, $c=9,3830-9,375 \AA$ ) $[6,7]$. Тернарні сполуки зі структурою типу $\mathrm{Pu}_{3} \mathrm{Pd}_{5}$ були також знайдені у споріднених системах \{Sm, Dy\}-Ga-Sn: $\mathrm{Sm}_{3} \mathrm{Ga}_{0,80-2,48} \mathrm{Sn}_{4,20-2,52}$ $(a=9,97522-9,89433, b=8,02642-7,87246, c=10,23304-9,91703 \AA)[8,9]$ та $\mathrm{Dy}_{3} \mathrm{Ga}_{2,54} \mathrm{Sn}_{2,46}(a=9,7300, b=7,7081, c=9,7925 \AA)$ [10].

(с) Деленко Т., Токайчук Я., Гладишевський Р., 2019 
Т. Деленко, Я. Токайчук, Р. Гладишевський

Метою цієї праці $\epsilon$ пошук тернарних сполук у системі Dy-Ga-Ge на ізоконцентраті 37,5 ат. \% Dy, що $є$ продовженням систематичного дослідження взаємодії компонентів у цій системі при $600^{\circ} \mathrm{C}$. Ізоконцентрата 37,5 ат. \% Dу системи Dy-Ga-Ge обмежена бінарними сполуками $\mathrm{Dy}_{3} \mathrm{Ga}_{5}\left(\mathrm{CT} \mathrm{Tm}_{3} \mathrm{Ga}_{5}\right.$; $\mathrm{C}$ о оР2; ПГ Рпта; $a=11,43, b=9,652, c=6,080 \AA$ ) [11] та $\mathrm{Dy}_{3} \mathrm{Ge}_{5}\left(\mathrm{CT} \mathrm{Y}_{3} \mathrm{Ge}_{5}\right.$; СП $o F 64$; ПГ Fdd2; $a=5,729, b=17,190, c=13,678 \AA$ ) [12].

\section{2. Матеріали та методика експерименту}

Сплави для дослідження синтезували сплавлянням шихти вихідних простих речовин (вміст основного компонента (мас. \%): Dy $\geq 99,9 ; \mathrm{Ga} \geq 99,99 ; \mathrm{Ge} \geq 99,999$ ) в електродуговій печі на мідному водоохолоджуваному поді 3 використанням вольфрамового електрода. Синтез проводили в атмосфері очищеного аргону (як гетер використовували пористий титан). Для досягнення однорідності сплави переплавляли двічі. Для гомогенізації сплави були запаяні у вакуумовані кварцові ампули та відпалені при $600^{\circ} \mathrm{C}$ впродовж 720 год у муфельній електропечі VULKAN A-550 з подальшим гартуванням у холодній воді без розбивання ампул. Втрати маси під час синтезу сплавів не перевищували $1 \%$. Рентгенофазовий аналіз здійснювали за масивами порошкових дифракційних даних, отриманими за кімнатної температури на дифрактометрі ДРОН-2.0М (проміння $\mathrm{Fe} K \alpha$ ). Його проводили порівнянням експериментальних дифрактограм синтезованих зразків 3 розрахованими дифрактограмами простих речовин, бінарних і тернарних сполук системи Dy-Ga-Ge за допомогою комплексу програм STOE WinXPow [13]. Кристалічну структуру сполук визначали рентгенівським дифракційним методом порошку за масивами даних, отриманими на дифрактометрі STOE Stadi P (проміння $\mathrm{Cu} K \alpha_{1}$ ). Уточнення параметрів профілю і структури проводили методом Рітвельда за допомогою комплексу програм FullProf Suite [14]. 3 огляду на близькі значення факторів розсіювання рентгенівського проміння атомами $\mathrm{Ga}$ i $\mathrm{Ge}$, склади статистичних сумішей цих атомів не уточнювали, а розраховували відповідно до складу фази, отриманого локальним рентгеноспектральним аналізом.

Локальний рентгеноспектральний аналіз проводили на растровому електронному мікроскопі PЕММА-102-02 з енергодисперсійним рентгенівським спектрометром ЕДАР. Сплави для аналізу заплавляли в тримачі сплавом Вуда, після чого шліфували та полірували до дзеркальної поверхні, застосовуючи наждачний папір 3 різною величиною зерен, а також дрібнодисперсний порошок $\mathrm{Cr}_{2} \mathrm{O}_{3}$. Загальний склад сплавів отримували на плоскій ділянці $\left(1 \times 1 \mathrm{~mm}^{2}\right)$. Локальний хімічний склад фази одержували усередненням точкових складів 4-5 зерен.

\section{3. Результати досліджень та їхнс обговорення}

У результаті рентгенофазового аналізу зразків з вмістом $35-40$ ат. \% Dу, 55-20 ат. \% Ga та 10-40 ат. \% Ge визначено існування двох нових тернарних сполук. Синтезовані зразки із зазначеної області були багатофазними, а їхні дифрактограми, крім відбиттів нових тернарних фаз, містили відбиття інших бінарних і тернарних фаз системи Dy-Ga-Ge, вказуючи на відповідні рівноваги при $600^{\circ} \mathrm{C}$. Для визначення складів та кристалічної структури тернарних сполук використано зразки складів $\mathrm{Dy}_{37,5} \mathrm{Ga}_{44} \mathrm{Ge}_{18,5}, \quad \mathrm{Dy}_{37,5} \mathrm{Ga}_{37,5} \mathrm{Ge}_{25}$ та $\mathrm{Dy}_{37,5} \mathrm{Ga}_{32,5} \mathrm{Ge}_{30}$, що, згідно 3 результатами рентгенофазового аналізу, містили найбільшу кількість нових фаз. Склади тернарних сполук, визначені локальним енергодисперсійним рентгенівським спектральним 
аналізом сплавів, становлять: Dy $\mathrm{Ga}_{3,5} \mathrm{Ge}_{1,5}, \mathrm{Dy}_{3} \mathrm{Ga}_{2,8} \mathrm{Ge}_{2,2}$ i Dy $\mathrm{Ga}_{2,4} \mathrm{Ge}_{2,6}$ (рис. 1, табл. 1). Стехіометрія $\mathrm{Dy}_{3} \mathrm{Ga}_{3,5} \mathrm{Ge}_{1,5}$ відповідає одній тернарній сполуці, тоді як склади $\mathrm{Dy}_{3} \mathrm{Ga}_{2,8} \mathrm{Ge}_{2,2}$ i $\mathrm{Dy}_{3} \mathrm{Ga}_{2,4} \mathrm{Ge}_{2,6}$ - іншій фазі, яка має область гомогенності вздовж ізоконцентрати 37,5 ат. \% Dу при $600^{\circ} \mathrm{C}$.

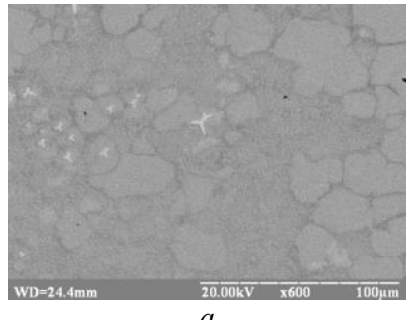

$a$

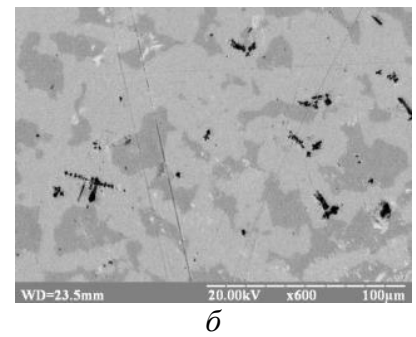

$\sigma$

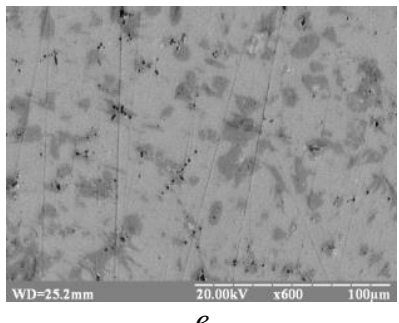

B $a-\mathrm{Dy}_{37,5} \mathrm{Ga}_{44} \mathrm{Ge}_{18,5} ; \sigma-\mathrm{Dy}_{37,5} \mathrm{Ga}_{37,5} \mathrm{Ge}_{25} ; \boldsymbol{\beta}-\mathrm{Dy}_{37,5} \mathrm{Ga}_{32,5} \mathrm{Ge}_{30}$

Fig. 1. Photographs in the secondary electrons of the polished surfaces of the samples: $a$ - Dy37.5Ga44Ge $18.5 ; 6$ - Dy37.5Ga37.5Ge25; 8 - Dy37.5Ga32.5 $\mathrm{Ge}_{30}$

Таблиия 1

Результати локального енергодисперсійного рентгенівського спектрального аналізу сплавів

Results of the local energy dispersive X-ray spectral analyses of the alloys

Table 1

\begin{tabular}{|lc|}
\hline & Вихідний склад сплаву $-\mathrm{Dy}_{37,5} \mathrm{Ga}_{44} \mathrm{Ge}_{18,5} *$ \\
Сіра фаза (основна) & $\mathrm{Dy}_{38(1)} \mathrm{Ga}_{43(1)} \mathrm{Ge}_{19(1)}\left(\mathrm{Dy}_{3} \mathrm{Ga}_{3,5} \mathrm{Ge}_{1,5}\right)$ \\
Темна фаза & $\mathrm{Dy}_{33(1)} \mathrm{Ga}_{54(1)} \mathrm{Ge}_{13(1)}\left(\mathrm{DyGa}_{1,6} \mathrm{Ge}_{0,4}\right)$ \\
\hline & Вихідний склад сплаву $-\mathrm{Dy}_{37,5} \mathrm{Ga}_{37,5} \mathrm{Ge}_{25} *$ \\
Сіра фаза (основна) & $\mathrm{Dy}_{38(1)} \mathrm{Ga}_{35(1)} \mathrm{Ge}_{27(1)}\left(\mathrm{Dy}_{3} \mathrm{Ga}_{2,8} \mathrm{Ge}_{2,2}\right)$ \\
Темна фаза & $\mathrm{Dy}_{33(1)} \mathrm{Ga}_{43(1)} \mathrm{Ge}_{24(1)}\left(\mathrm{DyGa}_{1,3} \mathrm{Ge}_{0,7}\right)$ \\
\hline & Вихідний склад сплаву $-\mathrm{Dy}_{37,5} \mathrm{Ga}_{32,5} \mathrm{Ge}_{30}{ }^{*}$ \\
Сіра фаза (основна) & $\mathrm{Dy}_{38(1)} \mathrm{Ga}_{30(1)} \mathrm{Ge}_{32(1)}\left(\mathrm{Dy}_{3} \mathrm{Ga}_{2,4} \mathrm{Ge}_{2,6}\right)$ \\
Темна фаза & $\mathrm{Dy}_{33(1)} \mathrm{Ga}_{43(1)} \mathrm{Ge}_{24(1)}\left(\mathrm{DyGa}_{1,3} \mathrm{Ge}_{0,7}\right)$ \\
\hline
\end{tabular}

* Світлі вкраплення - $\mathrm{Dy}_{2} \mathrm{O}_{3}$.

Подібність дифрактограми сполуки $\mathrm{Dy}_{3} \mathrm{Ga}_{3,5} \mathrm{Ge}_{1,5}$ до теоретично розрахованих дифрактограм бінарного галіду $\mathrm{Dy}_{3} \mathrm{Ga}_{5}$ i тернарної сполуки $\mathrm{Er}_{3} \mathrm{Ga}_{2,7} \mathrm{Ge}_{2,3}$ зі структурою типу $\mathrm{Tm}_{3} \mathrm{Ga}_{5}$ засвідчили їхню ізоструктурність. Уточнення кристалографічних параметрів тернарної фази $\mathrm{Dy}_{3} \mathrm{Ga}_{3,5} \mathrm{Ge}_{1,5}$ провели методом Рітвельда, керуючись координатами атомів сполуки $\mathrm{Er}_{3} \mathrm{Ga}_{2,7} \mathrm{Ge}_{2,3}$ [6], які взято за початкову модель. Крім основної фази, зразок містив 9,5(2) мас. \% $\mathrm{DyGa}_{1,6} \mathrm{Ge}_{0,4}\left(\mathrm{CT} \mathrm{AlB}_{2} ; h P 3\right.$, P6/mmm; $a=4,1795(4), c=4,0914(4) \AA$ ), що відповідає твердому розчину DyGa ${ }_{1,55} \mathrm{Ge}_{0-0,45}$ [4] та 1,2(11) мас. \% $\mathrm{Dy}_{2} \mathrm{O}_{3}\left(\mathrm{CT}\left(\mathrm{Mn}_{0,5} \mathrm{Fe}_{0,5}\right)_{2} \mathrm{O}_{3}\right.$; CП $c I 80 ;$ ПГ Ia-3; $a=10,666(5)$ $\AA$ А). Кристалічну структуру сполуки змінного складу $\mathrm{Dy}_{3} \mathrm{Ga}_{2,8-2,4} \mathrm{Ge}_{2,2-2,6}$ уточнено методом Рітвельда за дифрактограмами двох зразків. За початкову модель для уточнення взято координати атомів у структурі тернарної сполуки $\operatorname{Er}_{3} \mathrm{Ga}_{2,21-2,15} \mathrm{Ge}_{2,79-2,85}$ зі структурою типу $\mathrm{Pu}_{3} \mathrm{Pd}_{5}[6,7], 3$ огляду на подібність їхніх дифрактограм. Крім основної фази, зразки Dу ${ }_{37,5} \mathrm{Ga}_{37,5} \mathrm{Ge}_{25}$ та $\mathrm{Dy}_{37,5} \mathrm{Ga}_{32,5} \mathrm{Ge}_{30}$ містили $14,7(3)$ і 11,6(6) мас. \% фази складу $\mathrm{DyGa}_{1,3} \mathrm{Ge}_{0,7}\left(\mathrm{CT} \alpha-\mathrm{ThSi}_{2} ; \mathrm{C}\right.$ tII2; ПГ I4 1 /amd; $a=4,1753(7), c=14,4935(18) \AA$ для зразка $\mathrm{Dy}_{37,5} \mathrm{Ga}_{37,5} \mathrm{Ge}_{25}$ та $a=4,1748(8), c=14,494(2) \AA ̊$ для зразка $\left.\mathrm{Dy}_{37,5} \mathrm{Ga}_{32,5} \mathrm{Ge}_{30}\right)$ 3 області гомогенності тернарної сполуки $\mathrm{DyGa}_{1,40-1,25} \mathrm{Ge}_{0,60-0,75}$ [4] та 1,2(5) і 0,9(1) мас. \% $\mathrm{Dy}_{2} \mathrm{O}_{3}$, відповідно. 
Експериментальні, розраховані та різницеві дифрактограми зразків $\mathrm{Dy}_{37,5} \mathrm{Ga}_{44} \mathrm{Ge}_{18,5}, \quad \mathrm{Dy}_{37,5} \mathrm{Ga}_{37,5} \mathrm{Ge}_{25}$ та $\mathrm{Dy}_{37,5} \mathrm{Ga}_{32,5} \mathrm{Ge}_{30}$ зображено на рис. 2, умови експерименту та результати уточнення кристалічної структури фаз $\mathrm{Dy}_{3} \mathrm{Ga}_{3,5} \mathrm{Ge}_{1,5}$, $\mathrm{Dy}_{3} \mathrm{Ga}_{2,8} \mathrm{Ge}_{2,2}$ та $\mathrm{Dy}_{3} \mathrm{Ga}_{2,4} \mathrm{Ge}_{2,6}$ наведено у табл. 2. Незмінність параметрів елементарної комірки тернарної сполуки $\mathrm{Dy}_{3} \mathrm{Ga}_{3,5} \mathrm{Ge}_{1,5}$ у різних багатофазних зразках свідчить про ії постійний склад, тоді як аналіз параметрів елементарної комірки фази зі структурою типу $\mathrm{Pu}_{3} \mathrm{Pd}_{5}$ у різних зразках засвідчив, що склади $\mathrm{Dy}_{3} \mathrm{Ga}_{2,8} \mathrm{Ge}_{2,2}$ та $\mathrm{Dy}_{3} \mathrm{Ga}_{2,4} \mathrm{Ge}_{2,6}$ відповідають крайнім складам іiї області гомогенності.

Таблиия 2

Умови експерименту та результати уточнення кристалічної структури сполук $\mathrm{Dy}_{3} \mathrm{Ga}_{3,50} \mathrm{Ge}_{1,50}$ та $\mathrm{Dy}_{3} \mathrm{Ga}_{2,8-2,4} \mathrm{Ge}_{2,2-2,6}$

Table 2

Experimental conditions and results of the refinement of the crystal structures of the compounds $\mathrm{Dy}_{3} \mathrm{Ga}_{3.50} \mathrm{Ge}_{1.50}$ та $\mathrm{Dy}_{3} \mathrm{Ga}_{2.8-2.4} \mathrm{Ge}_{2.2-2.6}$

\begin{tabular}{|c|c|c|c|c|}
\hline \multicolumn{2}{|l|}{ Склад зразка, ат. \% } & $\mathrm{Dy}_{37,5} \mathrm{Ga}_{44} \mathrm{Ge}_{18,5}$ & $\mathrm{Dy}_{37,5} \mathrm{Ga}_{37,5} \mathrm{Ge}_{25}$ & $\mathrm{Dy}_{37,5} \mathrm{Ga}_{32,5} \mathrm{Ge}_{30}$ \\
\hline \multicolumn{2}{|l|}{ Фаза } & $\mathrm{Dy}_{3} \mathrm{Ga}_{3,5} \mathrm{Ge}_{1,5}$ & $\mathrm{Dy}_{3} \mathrm{Ga}_{2,8} \mathrm{Ge}_{2,2}$ & $\mathrm{Dy}_{3} \mathrm{Ga}_{2,4} \mathrm{Ge}_{2,6}$ \\
\hline \multicolumn{2}{|l|}{ Вміст фази, мас. \% } & $89,3(5)$ & $84,1(9)$ & $87,5(4)$ \\
\hline \multicolumn{2}{|l|}{ Структурний тип } & $\mathrm{Tm}_{3} \mathrm{Ga}_{5}$ & $\mathrm{Pu}_{3} \mathrm{Pd}_{5}$ & $\mathrm{Pu}_{3} \mathrm{Pd}_{5}$ \\
\hline \multicolumn{2}{|l|}{ Символ Пірсона } & $o P 32$ & $o S 32$ & $o S 32$ \\
\hline \multicolumn{2}{|l|}{ Просторова група } & Pnma & $\mathrm{Cmcm}$ & $\mathrm{Cmcm}$ \\
\hline \multicolumn{5}{|l|}{ Параметри елементарної } \\
\hline \multirow[t]{3}{*}{ комірки: } & $a, \AA$ & $11,6672(11)$ & $9,3738(11)$ & $9,3599(11)$ \\
\hline & $b, \AA$ & $9,4411(8)$ & $7,4816(9)$ & $7,4788(9)$ \\
\hline & $c, \AA$ & $6,0267(5)$ & $9,4068(11)$ & $9,4148(12)$ \\
\hline \multicolumn{2}{|l|}{ Об’єм комірки $V, \AA^{3}$} & $663,85(10)$ & $659,71(13)$ & $659,04(14)$ \\
\hline \multicolumn{2}{|c|}{ Кількість формульних одиниць $Z$} & 4 & 4 & 4 \\
\hline \multicolumn{2}{|c|}{ Густина $D \times, \Gamma \cdot \mathrm{cm}^{-3}$} & 8,494 & 8,226 & 8,181 \\
\hline \multicolumn{2}{|c|}{ Параметр текстури $G$ [напрям] } & $0,996(6)[001]$ & $0,949(4)[010]$ & $0,991(4)[010]$ \\
\hline \multirow[t]{3}{*}{ Параметри профілю: } & $U$ & $0,022(13)$ & $0,028(2)$ & $0,068(2)$ \\
\hline & $V$ & $0,024(12)$ & $0,079(12)$ & $-0,002(18)$ \\
\hline & $W$ & $0,007(2)$ & $-0,0035(4)$ & $0,012(4)$ \\
\hline \multicolumn{2}{|l|}{ Параметр змішування } & $0,641(16)$ & $0,605(16)$ & $0,594(18)$ \\
\hline \multirow[t]{2}{*}{ Параметри асиметрії: } & $P 1$, & $0,075(13)$ & $0,062(16)$ & $0,101(18)$ \\
\hline & $P 2$ & $-0,003(2)$ & $-0,003(2)$ & $0,011(3)$ \\
\hline \multirow[t]{5}{*}{ Фактори достовірності: } & $R_{\mathrm{B}}$ & 0,0608 & 0,0611 & 0,0639 \\
\hline & $R_{F}$ & 0,0951 & 0,0877 & 0,0930 \\
\hline & $R_{\mathrm{p}}$ & 0,0307 & 0,0295 & 0,0354 \\
\hline & $R_{\mathrm{wp}}$ & 0,0386 & 0,0371 & 0,0448 \\
\hline & $\chi^{2}$ & 0,993 & 1,07 & 1,01 \\
\hline
\end{tabular}

Кристалічна структура сполуки $\mathrm{Dy}_{3} \mathrm{Ga}_{3,5} \mathrm{Ge}_{1,5}$ належить до структурного типу $\mathrm{Tm}_{3} \mathrm{Ga}_{5}$ (СП oP32; ПГ Pnma; $\left.a=11,6672(11), b=9,4411(8), c=6,0267(5) \AA\right)$, a кристалічна структура сполуки $\mathrm{Dy}_{3} \mathrm{Ga}_{2,8-02,4} \mathrm{Ge}_{2,2-2,6}$ належить до структурного типу $\mathrm{Pu}_{3} \mathrm{Pd}_{5}$ (СП oS32; ПГ Cmcm; $a=9,3738(11)-9,3599(11), b=7,4816(9)-7,4788(9), c=$ 9,4068(11)-9,4148(12) А̊). Координати та ізотропні параметри зміщення атомів у структурах обох сполук наведено у табл. 3. Заміщення атомів $\mathrm{Ga}$ на атоми $\mathrm{Ge}$ в межах області гомогенності фази зі структурою типу $\mathrm{Pu}_{3} \mathrm{Pd}_{5}$ приводить до анізотропної зміни параметрів елементарної комірки: параметри $a$ i $b$ зменшуються, тоді як параметр $c$ - збільшується; водночас об'єм елементарної комірки зменшується. 
Т. Деленко, Я. Токайчук, Р. Гладишевський
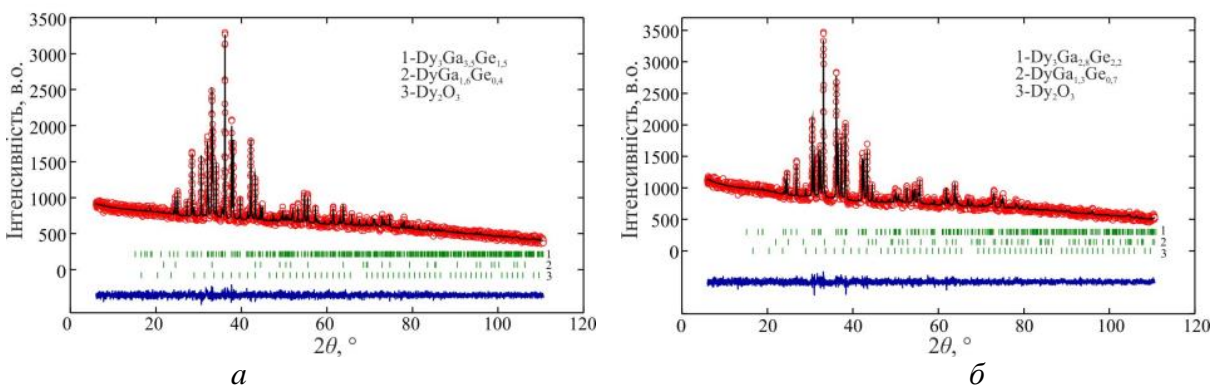

$a$

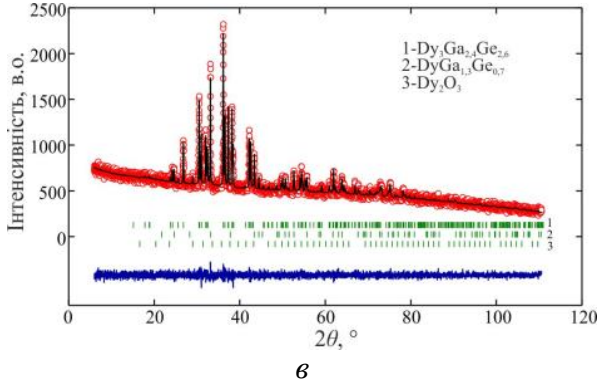

Рис. 2. Експериментальні (кружки), розраховані (лінії) та різницеві (знизу) дифрактограми

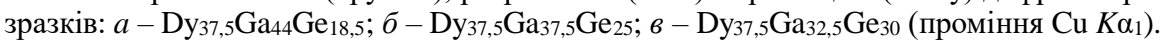
Вертикальні риски вказують на положення відбиттів індивідуальних фаз

Fig. 2. Experimental (circles), calculated (line) and difference (bottom) X-ray powder diffraction patterns of the samples: $a$ - Dy ${ }_{37.5} \mathrm{Ga}_{44} \mathrm{Ge}_{18.5} ; \sigma-\mathrm{Dy}_{37.5} \mathrm{Ga}_{37.5} \mathrm{Ge}_{25}$;

8 - Dy ${ }_{37.5} \mathrm{Ga}_{32.5} \mathrm{Ge}_{30}\left(\mathrm{Cu} K \alpha_{1}\right.$ radiation). Vertical bars indicate the positions of reflections for individual phases

Обидві структури характеризуються двома правильними системами точок атомів Dу та чотирма чи трьома ПСТ, зайнятих статистичними сумішами атомів $\mathrm{Ga}$ i $\mathrm{Ge}$. Варто зазначити, що у системі Dy-Ga при $600^{\circ} \mathrm{C}$ існує бінарна сполука $\mathrm{Dy}_{3} \mathrm{Ga}_{5}$ зі структурою типу $\mathrm{Tm}_{3} \mathrm{Ga}_{5}$ [11]. Відмінні параметри елементарної комірки фаз $\mathrm{Dy}_{3} \mathrm{Ga}_{3,5} \mathrm{Ge}_{1,5}$ i $\mathrm{Dy}_{3} \mathrm{Ga}_{5}$, a також результати рентгенофазового аналізу низки трикомпонентних сплавів (ізоструктурні сполуки не перебувають у рівновазі при $600^{\circ} \mathrm{C}$ ) дають підстави стверджувати, що за температури дослідження фаза $\mathrm{Dy}_{3} \mathrm{Ga}_{3,5} \mathrm{Ge}_{1,5} \in$ індивідуальною тернарною сполукою, a не частиною твердого розчину на основі бінарного галіду $\mathrm{Dy}_{3} \mathrm{Ga}_{5}$. Знайдені тернарні сполуки $\mathrm{Dy}_{3} \mathrm{Ga}_{3,5} \mathrm{Ge}_{1,5}$ та $\mathrm{Dy}_{3} \mathrm{Ga}_{2,8-2,4} \mathrm{Ge}_{2,2-2,6}$ не перебувають у рівновазі при $600^{\circ} \mathrm{C}$.

Міжатомні віддалі, координаційні числа та координаційні многогранники атомів у структурах сполук $\mathrm{Dy}_{3} \mathrm{Ga}_{3,5} \mathrm{Ge}_{1,5}$ та $\mathrm{Dy}_{3} \mathrm{Ga}_{2,8-2,4} \mathrm{Ge}_{2,2-2,6}$ (для складу $\mathrm{Dy}_{3} \mathrm{Ga}_{2,4} \mathrm{Ge}_{2,6}$ ) наведено у табл. 4 та 5, відповідно.

Координаційними многогранниками атомів Dу в обох структурах є 15- та 17-вершинники псевдо Франка-Каспера. Координаційними многогранниками атомів малого розміру є тригональні призми з чотирма додатковими атомами та дефектні ікосаедри. Найкоротшими віддалями у структурі сполуки $\mathrm{Dy}_{3} \mathrm{Ga}_{3,5} \mathrm{Ge}_{1,5} є$ віддалі між положеннями $M 1-M 3$ та $M 1-M 2$ статистичної суміші атомів $\mathrm{Ga}$ та $\mathrm{Ge}$ : $\delta_{M 1-M 3}=2,633(19) \AA ̊$ i $\delta_{M 1-M 2}=2,653(18) \AA$, в структурі сполуки $\mathrm{Dy}_{3} \mathrm{Ga}_{2,4} \mathrm{Ge}_{2,6}$ найкоротшими віддалями є також віддалі між положеннями $M 1-M 3$ та $M 1-M 2$ : $\delta_{M 1-M 3}=2,664(11) \AA$ i $\delta_{M 1-M 2}=2,668(8) \AA$. Статистичні суміші атомів Ga i Ge в обох 
структурах утворюють ізольовані тетрагональні піраміди, які можна інтерпретувати як arachno-кластери типу Вейда [15]. У структурі сполуки $\mathrm{Dy}_{3} \mathrm{Ga}_{3,5} \mathrm{Ge}_{1,5}$ ці піраміди мають склад $M 4 M 1_{2} M 2 M 3\left(\delta_{M 1-M 3}=2,633(19) \AA \AA, \delta_{M 1-M 2}=2,653(18), \delta_{M 4-M 2}=2,72(2)\right.$, $\left.\delta_{M 4-M 3}=2,77(4), \quad \delta_{M 4-M 1}=2,872(19) \AA\right)$, а в структурі сполуки Dу $_{3} \mathrm{Ga}_{2,4} \mathrm{Ge}_{2,6}$ $M 3 M 1_{2} M 2_{2}\left(\delta_{M 1-M 3}=2,664(11) \AA, \delta_{M 1-M 2}=2,668(8), \delta_{M 2-M 3}=2,762(12) \AA\right)$ (рис. 3).

Таблиия 3

Координати, коефіцієнти заповнення позицій та ізотропні параметри зміщення атомів у структурах сполук $\mathrm{Dy}_{3} \mathrm{Ga}_{3,5} \mathrm{Ge}_{1,5}$ та $\mathrm{Dy}_{3} \mathrm{Ga}_{2,8-2,4} \mathrm{Ge}_{2,2-2,6}$

Table 3

Coordinates, occupancies and isotropic displacement parameters of the atoms in the structures of the

\begin{tabular}{|c|c|c|c|c|c|}
\hline Атом & ПСТ & $x$ & $y$ & $z$ & $B_{\text {iso }}, \AA^{2}$ \\
\hline \multicolumn{6}{|c|}{$\begin{array}{l}\mathrm{Dy}_{3} \mathrm{Ga}_{3,5} \mathrm{Ge}_{1,5}\left(\mathrm{Tm}_{3} \mathrm{Ga}_{5} ; o P 32 ; \text { Pnma; } a=11,6672(11), b=9,4411(8), c=6,0267(5) \AA ;\right. \\
M 1=M 2=M 3=M 4=0.70 \mathrm{Ga}+030 \mathrm{Ge})\end{array}$} \\
\hline Dy1 & $8 d$ & $0,3519(5)$ & $0,0035(6)$ & $0,3840(10)$ & $0,51(12)$ \\
\hline Dy2 & $4 c$ & $0,4238(6)$ & $1 / 4$ & $0,8604(17)$ & $0,62(18)$ \\
\hline$M 1$ & $8 d$ & $0,0875(6)$ & $0,0560(7)$ & $0,3782(2)$ & \multirow{4}{*}{$1,63(15)$} \\
\hline$M 2$ & $4 c$ & $0,0011(14)$ & $1 / 4$ & $0,1066(4)$ & \\
\hline M3 & $4 c$ & $0,2027(12)$ & $1 / 4$ & $0,5990(5)$ & \\
\hline$M 4$ & $4 c$ & $0,2336(13)$ & $1 / 4$ & $0,1440(5)$ & \\
\hline \multicolumn{6}{|c|}{$\begin{array}{l}\mathrm{Dy}_{3} \mathrm{Ga}_{2,8} \mathrm{Ge}_{2,2}\left(\mathrm{Pu}_{3} \mathrm{Pd} ;\right. \\
M 1=M 332 ; C m c m ; a=9,3738(11), b=7,4816(8), c=9,4068(11) \AA\end{array}$} \\
\hline Dy1 & $8 e$ & $0,2001(5)$ & 0 & 0 & $0,47(12)$ \\
\hline Dy2 & $4 c$ & 0 & $0,6480(8)$ & $1 / 4$ & $0,58(13)$ \\
\hline$M 1$ & $8 g$ & $0,2015(10)$ & $0,2971(11)$ & $1 / 4$ & \\
\hline$M 2$ & $8 f$ & 0 & $0,3145(12)$ & $0,0551(7)$ & $1,58(15)$ \\
\hline M3 & $4 c$ & 0 & $0,0433(17)$ & $1 / 4$ & \\
\hline \multicolumn{6}{|c|}{$\begin{array}{l}\mathrm{Dy}_{3} \mathrm{Ga}_{2,4} \mathrm{Ge}_{2,6}\left(\mathrm{Pu}_{3} \mathrm{Pd}_{5} ; o S 32 ; C m c m ; a=9,3599(11), b=7,4788(9), c=9,4148(12) \AA\right. \\
M 1=M 2=M 3=0,48 \mathrm{Ga}+0,52 \mathrm{Ge})\end{array}$} \\
\hline Dy1 & $8 e$ & $0,1987(4)$ & 0 & 0 & $0,50(13)$ \\
\hline Dy2 & $4 c$ & 0 & $0,6508(8)$ & $1 / 4$ & $0,52(17)$ \\
\hline M1 & $8 g$ & $0,2034(9)$ & $0,2919(10)$ & $1 / 4$ & \\
\hline$M 2$ & $8 f$ & 0 & $0,3157(12)$ & $0,0524(7)$ & $1,46(14)$ \\
\hline M3 & $4 c$ & 0 & $0,0428(15)$ & $1 / 4$ & \\
\hline
\end{tabular}
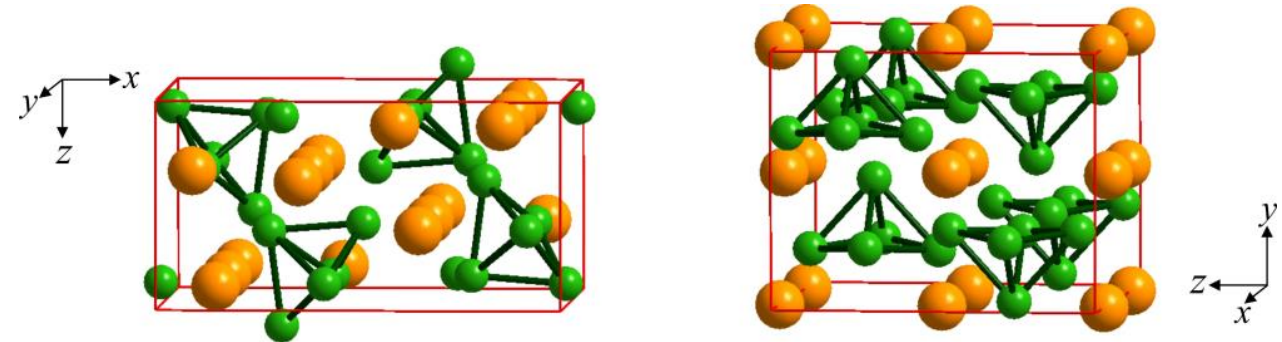

Рис. 3. Вміст елементарних комірок і тетрагонально-пірамідальні кластери у структурах сполук $\mathrm{Dy}_{3} \mathrm{Ga}_{3,5} \mathrm{Ge}_{1,5}$ (a) та $\mathrm{Dy}_{3} \mathrm{Ga}_{2,4} \mathrm{Ge}_{2,6}$ (б)

Fig. 3. Content of the unit cells and square pyramidal arachno-type clusters in the structures of $\mathrm{Dy}_{3} \mathrm{Ga}_{3.5} \mathrm{Ge}_{1.5}(a)$ and $\mathrm{Dy}_{3} \mathrm{Ga}_{2.4} \mathrm{Ge}_{2.6}(\sigma)$ 
Т. Деленко, Я. Токайчук, Р. Гладишевський

Таблиия 4

Міжатомні віддалі $(\delta)$, координаційні числа (КЧ) та координаційні многогранники (КМ) атомів у структурі сполуки $\mathrm{Dy}_{3} \mathrm{Ga}_{3,5} \mathrm{Ge}_{1,5}(M=0,70 \mathrm{Ga}+0,30 \mathrm{Ge})$

Table 4

Interatomic distances $(\delta)$, coordination numbers $(\mathrm{K \Psi})$ and coordination polyhedra $(\mathrm{KM})$ of atoms in the structure of the compound $\mathrm{Dy}_{3} \mathrm{Ga}_{3.5} \mathrm{Ge}_{1.5}(M=0.70 \mathrm{Ga}+0.30 \mathrm{Ge})$

\begin{tabular}{|c|c|c|c|c|}
\hline \multicolumn{5}{|c|}{$\mathrm{Dy}_{3} \mathrm{Ga}_{3,5} \mathrm{Ge}_{1,5}$} \\
\hline \multicolumn{2}{|c|}{ Атоми } & $\delta, \AA$ & KЧ & KM \\
\hline \multicolumn{2}{|c|}{1} & 2 & 3 & 4 \\
\hline \multirow[t]{16}{*}{ Dy1 } & $-M 2$ & $2,907(11)$ & \multirow{16}{*}{17} & \\
\hline & $-M 3$ & $3,014(18)$ & & \\
\hline & $-M 4$ & $3,029(17)$ & & \\
\hline & $-M 4$ & $3,068(17)$ & & \\
\hline & $-M 1$ & $3,111(13)$ & & \\
\hline & $-M 1$ & $3,123(9)$ & & \\
\hline & $-M 1$ & $3,181(13)$ & & \\
\hline & $-M 3$ & $3,181(16)$ & & \\
\hline & $-M 1$ & $3,210(10)$ & & \\
\hline & $-M 2$ & $3,237(14)$ & & \\
\hline & - Dy1 & $3,731(8)$ & & \\
\hline & - Dy2 & $3,790(10)$ & & \\
\hline & -2 Dy1 & $3,838(8)$ & & \\
\hline & - Dy2 & $3,841(8)$ & & \\
\hline & - Dy2 & $4,010(10)$ & & \\
\hline & - Dy2 & $4,011(8)$ & & \\
\hline \multirow[t]{11}{*}{ Dy2 } & $-M 4$ & $2,80(2)$ & \multirow{11}{*}{17} & \\
\hline & $-2 M 1$ & $2,894(7)$ & & \\
\hline & $-M 2$ & $2,96(3)$ & & \\
\hline & $-M 3$ & $3,02(2)$ & & \\
\hline & $-2 M 1$ & $3,080(11)$ & & \\
\hline & $-M 3$ & $3,263(17)$ & & \\
\hline & $-M 2$ & $3,33(3)$ & & \\
\hline & -2 Dy1 & $3,790(10)$ & & \\
\hline & -2 Dy1 & $3,841(8)$ & & \\
\hline & -2 Dy1 & $4,010(10)$ & & \\
\hline & -2 Dy1 & $4,011(8)$ & & \\
\hline \multirow[t]{10}{*}{$M 1$} & $-M 3$ & $2,633(19)$ & \multirow{10}{*}{10} & \\
\hline & $-M 2$ & $2,653(18)$ & & \\
\hline & $-M 1$ & $2,729(12)$ & & \\
\hline & $-M 4$ & $2,872(19)$ & & \\
\hline & - Dy2 & $2,894(17)$ & & \\
\hline & - Dy2 & $3,080(11)$ & & \\
\hline & - Dy1 & $3,111(13)$ & & \\
\hline & - Dy1 & $3,123(9)$ & & $1 \mathrm{Dy}_{6}$ \\
\hline & - Dy1 & $3,181(13)$ & & \\
\hline & - Dy1 & $3,210(10)$ & & \\
\hline
\end{tabular}


Т. Деленко, Я. Токайчук, Р. Гладишевський

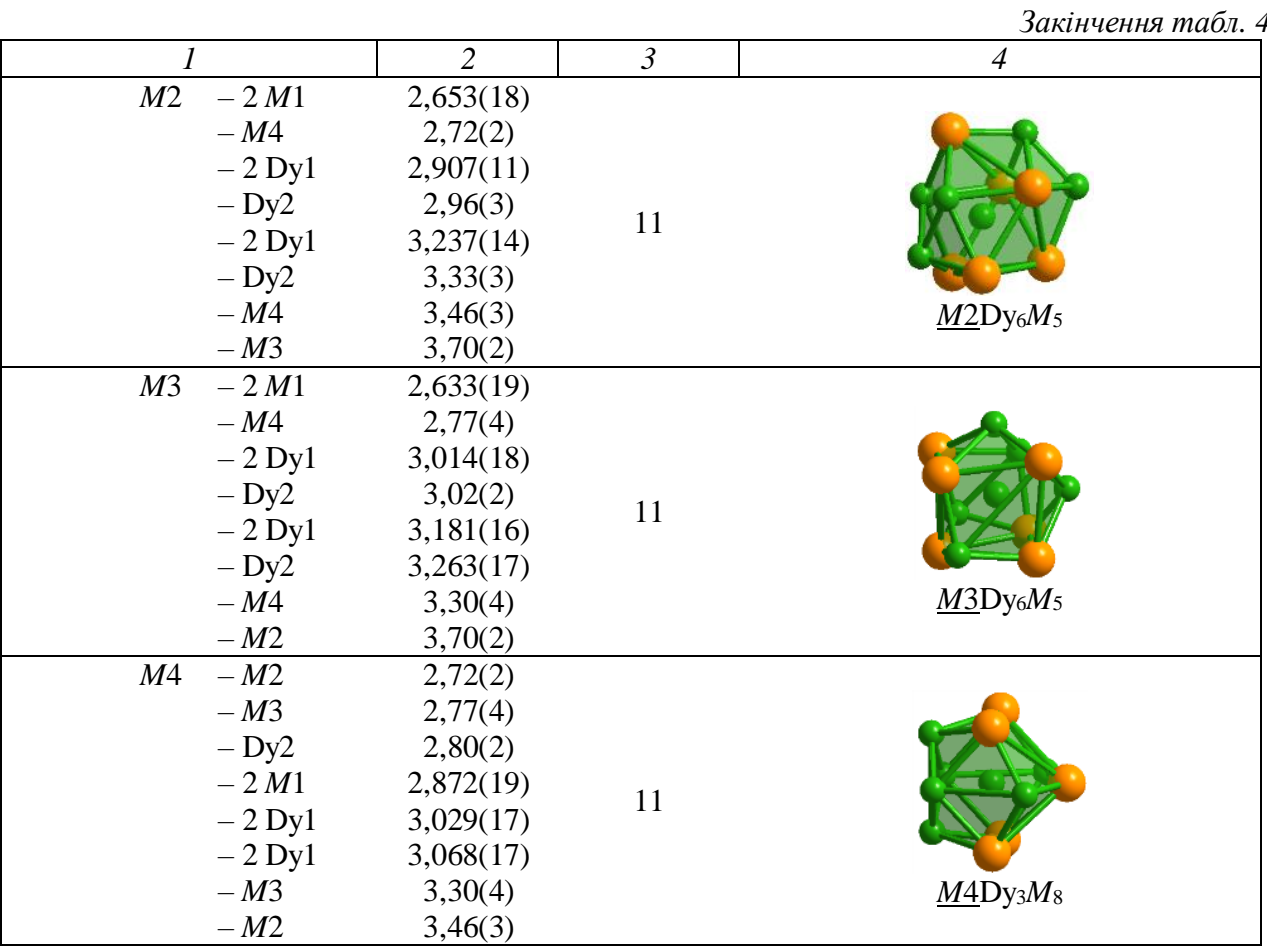

Таблиия 5 Міжатомні віддалі $(\delta)$, координаційні числа (КЧ) та координаційні многогранники (КМ) атомів у структурі $\mathrm{Dy}_{3} \mathrm{Ga}_{2,4} \mathrm{Ge}_{2,6}(M=0,48 \mathrm{Ga}+0,52 \mathrm{Ge})$

Table 5

Interatomic distances $(\delta)$, coordination numbers $(\mathrm{K \Psi})$ and coordination polyhedra $(\mathrm{KM})$ of atoms in the structure of $\mathrm{Dy}_{3} \mathrm{Ga}_{2 .} \mathrm{Ge}_{2.6}(M=0.48 \mathrm{Ga}+0.52 \mathrm{Ge})$

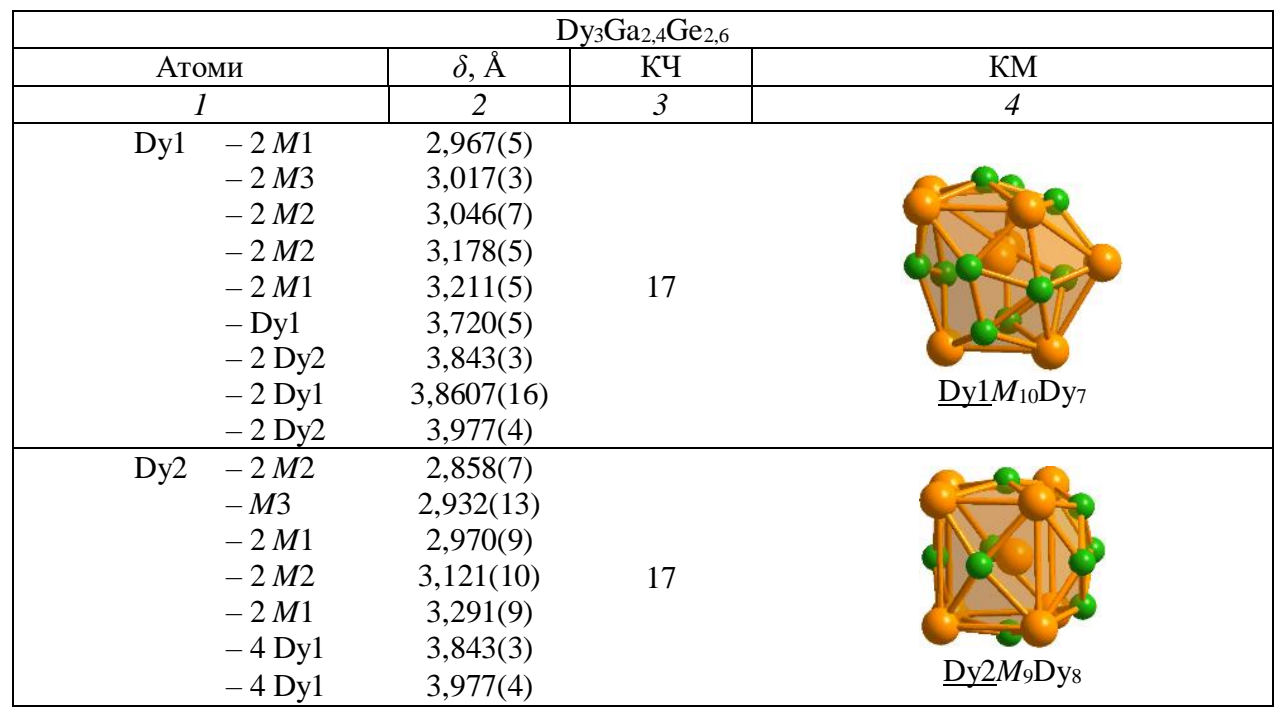


Т. Деленко, Я. Токайчук, Р. Гладишевський

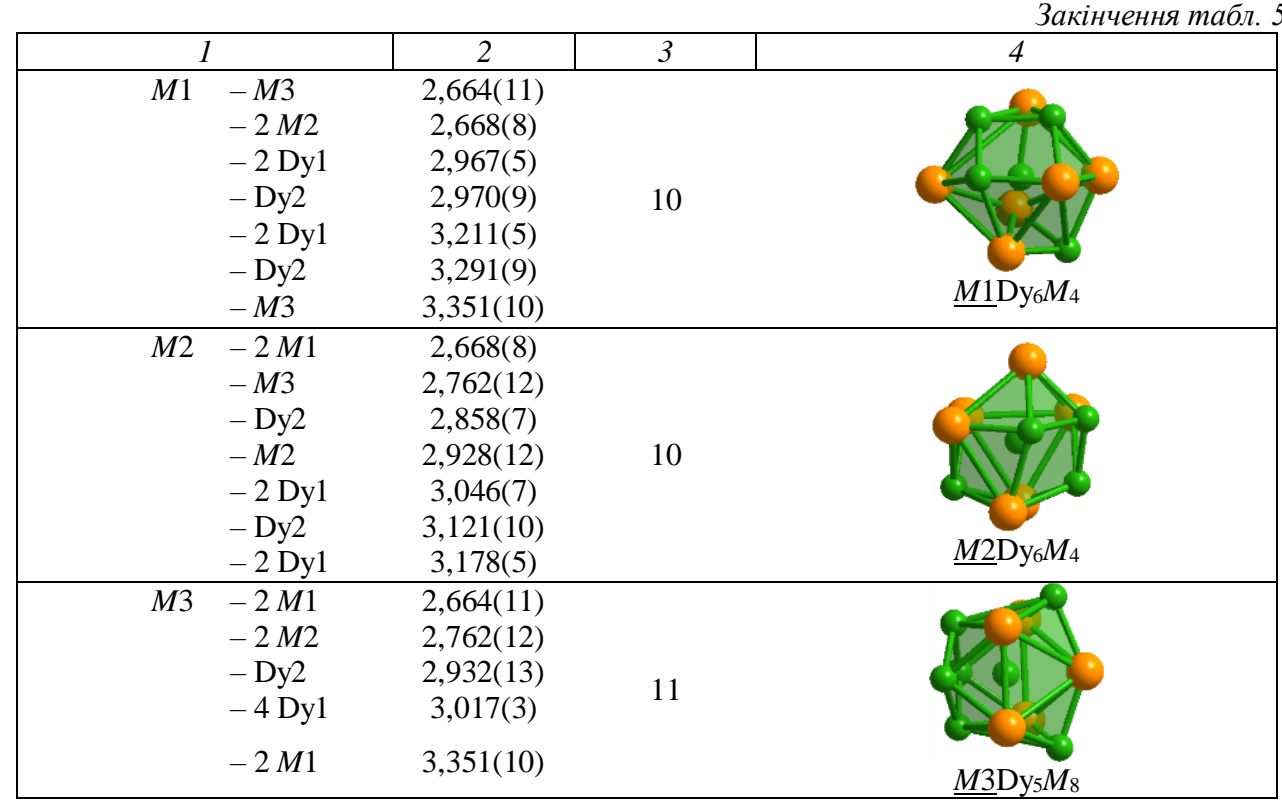

Структурні типи $\mathrm{Tm}_{3} \mathrm{Ga}_{5}$ та $\mathrm{Pu}_{3} \mathrm{Pd}_{5}$, до яких належать структури сполук $\mathrm{Dy}_{3} \mathrm{Ga}_{3,5} \mathrm{Ge}_{1,5}$ та $\mathrm{Dy}_{3} \mathrm{Ga}_{2,8-2,4} \mathrm{Ge}_{2,2-2,6}, \epsilon$ близькоспорідненими. Вони належать до родини деформованих похідних структури типу $\mathrm{Rh}_{5} \mathrm{Ge}_{3}$ [16]. Головною особливістю структурних типів $\mathrm{Rh}_{5} \mathrm{Ge}_{3}, \mathrm{Yb}_{5} \mathrm{Sb}_{3}$ [17], $\mathrm{U}_{3} \mathrm{~S}_{5}$ [18], $\mathrm{Y}_{5} \mathrm{Bi}_{3}$ [19], $\mathrm{Tm}_{3} \mathrm{Ga}_{5}$ [6] та $\mathrm{Pu}_{3} \mathrm{Pd}_{5}$ [20] $\epsilon$ каркаси атомів, утворені з'єднаними колонами з заповнених тригональних призм (рис. 4) [21]. Ці призми у колонах з'єднані трикутними гранями, а колони між собою - ребрами призм сусідніх колон, утворюючи тривимірний каркас 3 великими деформованими гексагональними призмами, що утворюють канали. У структурах сполук $\mathrm{Dy}_{3} \mathrm{Ga}_{3,5} \mathrm{Ge}_{1,5}$ та $\mathrm{Dy}_{3} \mathrm{Ga}_{2,4} \mathrm{Ge}_{2,6}$ всередині кожної гексагональної призми $є$ два атоми малого розміру, а в площині кожної шестикутної основи призми розташований атом Dy. У структурах типів $\mathrm{Tm}_{3} \mathrm{Ga}_{5}$ та $\mathrm{Pu}_{3} \mathrm{Pd}_{5}$ гексагональні призми $\epsilon$ сильно деформованими порівняно з призмами у структурі $\mathrm{Rh}_{5} \mathrm{Ge}_{3}$. У структурах типів $\mathrm{Yb}_{5} \mathrm{Sb}_{3}$ та $\mathrm{Yb}_{5} \mathrm{Bi}_{3}$ деформація $\epsilon$ меншою. Структурний тип $\mathrm{U}_{3} \mathrm{~S}_{5} \epsilon$ антитипом до структури $\mathrm{Yb}_{5} \mathrm{Sb}_{3}$.

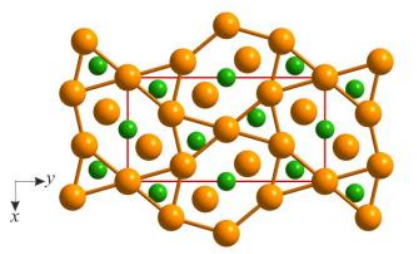

$a$

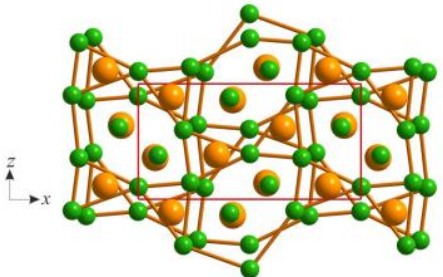

6

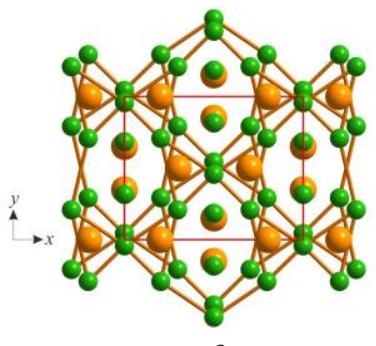

B

Fig. 4. Projections of the structures of $\mathrm{Rh}_{5} \mathrm{Ge}_{3}(a), \mathrm{Dy}_{3} \mathrm{Ga}_{3.5} \mathrm{Ge}_{1.5}\left(\right.$ () and $\mathrm{Dy}_{3} \mathrm{Ga}_{2.4} \mathrm{Ge}_{2.6}($ ( ) 


\section{4. Висновки}

Тернарні сполуки $\mathrm{Dy}_{3} \mathrm{Ga}_{3,5} \mathrm{Ge}_{1,5}$ (CT $\left.\mathrm{Tm}_{3} \mathrm{Ga}_{5}\right)$ i $\mathrm{Dy}_{3} \mathrm{Ga}_{2,8-2,4} \mathrm{Ge}_{2,2-2,6}\left(\mathrm{CT} \mathrm{Pu}_{3} \mathrm{Pd}_{5}\right)$ існують на ізоконцентраті 37,5 ат. \% Dу системи Dy-Ga-Ge при $600^{\circ} \mathrm{C}$. Під час заміщення атомів $\mathrm{Ga}$ на атоми $\mathrm{Ge}$ в області гомогенності сполуки зі структурою типу $\mathrm{Pu}_{3} \mathrm{Pd}_{5}$ параметри елементарної комірки змінюються анізотропно: параметри $a \mathrm{i} b$ зменшуються, тоді як параметр $c$ - збільшується; водночас об'єм елементарної комірки зменшується. У кристалічних структурах обох сполук можна виділити ізольовані тетрагонально-пірамідальні кластери, утворені атомами $p$-елементів, інтерпретовані як arachno-кластери типу Вейда. Структурні типи $\mathrm{Tm}_{3} \mathrm{Ga}_{5}$ та $\mathrm{Pu}_{3} \mathrm{Pd}_{5}$ належать до родини деформованих похідних структури типу $\mathrm{Rh}_{5} \mathrm{Ge}_{3}$, що, на загал, характеризується взаємноз'єднаними колонами заповнених тригональних призм, які утворюють великі гексагональні канали.

1. Villars P., Cenzual K. (Eds.). Pearson's Crystal Data - Crystal Structure Database for Inorganic Compounds. Materials Park: ASM International (OH), Release 2017/18.

2. Tokaychuk Ya., Delenko T., Gladyshevskii R. Crystal structure of $\mathrm{Dy}_{2} \mathrm{Ga}_{1.8} \mathrm{Ge}_{5.2} / /$ Chem. Met. Alloys. 2013. Vol. 6. P. 220-224.

3. Delenko T., Horyn A., Tokaychuk Ya., Gladyshevskii R. Crystal structures and electrical properties of the ternary compounds $\mathrm{DyGa}_{3-x} \mathrm{Ge}_{x} \quad(x=0.08-0.48$ and $x=0.68-0.80$ ) // Solid State Phenom. 2019. Vol. 289. P. 53-58.

4. Tokaychuk Ya., Delenko T., Gladyshevskii R. Structure transformations in $\mathrm{DyGa}_{2-x} \mathrm{Ge}_{x}$ $(0 \leq x \leq 0.6) \quad / /$ Visnyk Lviv Univ. Ser. Chem. 2014. Iss. 55(1). P. 47-53 (in Ukrainian).

5. Pukas S., Melnyk A., Kuprysyuk V., Gladyshevskii R. Influence of the Ga(In) additions on the structure of digermanides of Dy, Ho and Er // Coll. Abs. 9 Sci. conf. "Lviv Chemical Readings - 2003”. Lviv, May 21-23, 2003. P. H36 (in Ukrainian).

6. Venturini G., Vernière A., Malaman B. Evolution of the non-stoichiometry in the $\mathrm{Er}\left(\mathrm{Ge}_{1-x} \mathrm{Ga}_{x}\right)_{2}$ compounds: crystal structure of $\mathrm{Er}_{4}(\mathrm{Ge}, \mathrm{Ga})_{7}$, a new hexagonal $\mathrm{AlB}_{2}$ derivative // J. Alloys Compd. 1999. Vol. 291. P. 201-207. DOI: https://doi.org/10.1016/S0925-8388(99)00276-5

7. Welter R., Venturini G. Trierbium digallide trigermanide // Acta Crystallogr., Sect. C: Cryst. Struct. Commun. 1999. Vol. 55. P. 1969-1970.

DOI: https://doi.org/10.1107/S0108270199010501

8. Tokaychuk Ya. O., Filinchuk Ya. E., Fedorchuk A. O., Bodak O. I. Partial Sn-atom ordering in $\mathrm{Sm}_{3} \mathrm{Ga}_{0.80-2.48} \mathrm{Sn}_{4.20-2.52} / /$ Acta Crystallogr., Sect. C: Cryst. Struct. Commun. 2003. Vol. 59. P. i125-i127. DOI: https://doi.org/10.1107/S0108270103024776

9. Tokaychuk $Y a$. The ternary system $\mathrm{Sm}-\mathrm{Ga}-\mathrm{Sn}$ : isothermal section of the phase diagram at $600^{\circ} \mathrm{C}$ and crystal structures of the compounds // Chem. Met. Alloys. 2015. Vol. 8. P. 112-122.

10. Fedyna V., Tokaychuk Ya., Gladyshevskii R. Crystal structure of the compound $\mathrm{Dy}_{3} \mathrm{Ga}_{2.54} \mathrm{Sn}_{2.46} / /$ Chem. Met. Alloys. 2012. Vol. 5. P. 160-165.

11. Yatsenko S. P., Gladyshevskii, E. I. Tschuntonow K. A., Yarmolyuk Ya. P., Grin Yu. Kristallstruktur von $\mathrm{Tm}_{3} \mathrm{Ga}_{5}$ und analoger verbindungen // J. Less-Common Met. 1983. Vol. 91. P. 21-32. DOI: https://doi.org/10.1016/0022-5088(83)90092-9 
12. Schobinger Papamantellos P., De Mooij D. B., Buschow K. H. J. Crystallographic and magnetic structure of $\mathrm{Dy}_{3} \mathrm{Ge}_{5}$ and DyGe $\mathrm{D}_{1.9}$ // J. Less-Common Met. 1990. Vol. 163. P. 319-330. DOI: https://doi.org/10.1016/0022-5088(90)90598-E

13. STOE WinXPow (Version 2.21). - Darmstadt : Stoe \& Cie, 2005.

14. Rodríguez-Carvajal J. Recent developments of the Program FULLPROF // Commission on Powder Diffraction (IUCr). Newsletter. 2001. Vol. 26. P. 12-19.

15. Zürcher F., Nesper R., Hoffmann S., Fässler T. F. Novel arachno-type $\mathrm{X}_{5}{ }^{6-}$ Zintl anions in $\mathrm{Sr}_{3} \mathrm{Sn}_{5}, \mathrm{Ba}_{3} \mathrm{Sn}_{5}$, and $\mathrm{Ba}_{3} \mathrm{~Pb}_{5}$ and charge influence on Zintl clusters // Z. Anorg. Allg. Chem. 2001. Vol. 627. P. 2211-2219. DOI: https://doi.org/10.1002/chin.200148013

16. Geller $S$. The rhodium-germanium system. I. The crystal structures of $\mathrm{Rh}_{2} \mathrm{Ge}, \mathrm{Rh}_{5} \mathrm{Ge}_{3}$ and RhGe // Acta Crystallogr. 1955. Vol. 8. P. 15-21. DOI: https://doi.org/10.1107/S0365110X55000030

17. Brunton G. D., Steinfink $H$. The crystal structure of $\beta$-ytterbium triantimonide, a lowtemperature phase // Inorg. Chem. 1971. Vol. 10. P. 2301-2303. DOI: http://dx.doi.org/10.1021/ic50104a042

18. Potel M., Brochu R., Padiou J., Grandjean D. Etude structurale du sulfure $\mathrm{U}_{3} \mathrm{~S}_{5} / /$ C. R. Seances Acad. Sci., Ser. C. 1972. Vol. 275. P. 1419-1421.

19. Wang Y., Gabe E. J., Calvert L. D., Taylor J. B. The crystal structure of $\mathrm{Y}_{5} \mathrm{Bi}_{3}$ and its relation to the $\mathrm{Mn}_{5} \mathrm{Si}_{3}$ and the $\mathrm{Yb}_{5} \mathrm{Sb}_{3}$ type structures // Acta Crystallogr., Sect. B: Struct. Crystallogr. Cryst. Chem. 1976. Vol. 32. P. 1440-1445. DOI: https://doi.org/10.1107/S0567740876005529

20. Cromer D. T. Plutonium-palladium $\mathrm{Pu}_{3} \mathrm{Pd}_{5} / /$ Acta Crystallogr., Sect. B: Struct. Crystallogr. Cryst. Chem. 1976. Vol. 32. P. 1930-1932. DOI: https://doi.org/10.1107/S0567740876006778

21. Gladyshevskii R. E., Cenzual K., Zhao J. T., Parthé E. $\mathrm{Ce}_{5} \mathrm{RuGe}_{2}$ with a $\mathrm{Y}_{2} \mathrm{HfS}_{5}$ anti-type structure, an ordered substitution variant of orthorhombic $\beta-\mathrm{Yb}_{5} \mathrm{Sb}_{3} / /$ Acta Crystallogr., Sect. C: Cryst. Struct. Commun. 1992. Vol. 48. P. 221-225. DOI: https://doi.org/10.1107/S010827019100971X

\title{
CRYSTAL STRUCTURE OF THE COMPOUNDS $D_{3} \mathrm{Ga3}_{.5} \mathrm{Ge}_{1.5}$ AND Dy3 $\mathrm{Ga}_{2.8-2.4} \mathrm{Ge}_{2.2-2.6}$
}

\author{
T. Delenko*, Ya. Tokaychuk, R. Gladyshevskii \\ Ivan Franko National University of Lviv, \\ Kyryla i Mefodiya Str.. 6, 79005 Lviv, Ukraine \\ e-mail:tarasdelenko@gmail.com
}

Two new ternary compounds, $\mathrm{Dy}_{3} \mathrm{Ga}_{3.5} \mathrm{Ge}_{1.5}$ and $\mathrm{Dy}_{3} \mathrm{Ga}_{2.8-2.4} \mathrm{Ge}_{2.2-2.6}$, were found in the system Dy-Ga-Ge at $600^{\circ} \mathrm{C}$. Their compositions were established by means of energy-dispersive $\mathrm{X}$-ray spectral analysis and the crystal structures were determined by X-ray powder diffraction: $\mathrm{Dy}_{3} \mathrm{Ga}_{3.5} \mathrm{Ge}_{1.5}$ (structure type $\mathrm{Tm}_{3} \mathrm{Ga}_{5}$; Pearson symbol $o$ P32; space group Pnma; $a=11.6672(11)$, $b=9.4411(8), c=6.0267(5) \AA)$ and $\mathrm{Dy}_{3} \mathrm{Ga}_{2.8-2.4} \mathrm{Ge}_{2.2-2.6}\left(\mathrm{Pu}_{3} \mathrm{Pd}_{5} ; o S 32 ; C m c m ; a=9.3738(11)-9.3599(11)\right.$, 
$b=7.4816(8)-7.4788(9), c=9.4068(11)-9.4148(12) \AA$ ). Substitution of Ge atoms for Ga atoms within the homogeneity range of the $\mathrm{Pu}_{3} \mathrm{Pd}_{5}$-type phase is accompanied by an anisotropic change of the unit-cell parameters: the parameters $a$ and $b$ decrease, whereas the parameter $c$ increases; the unitcell volume decreases. The coordination polyhedra of the Dy atoms in both structures are 15- and 17vertex pseudo Frank-Kasper polyhedra. The coordination environments of the $p$-element atoms (statistical mixtures of $\mathrm{Ga}$ and $\mathrm{Ge}$ atoms) are trigonal prisms with four additional atoms and defect icosahedra.

In the structures of the compounds $D_{y_{3}} \mathrm{Ga}_{3.5} \mathrm{Ge}_{1.5}$ and $\mathrm{Dy}_{3} \mathrm{Ga}_{2.8-2.4} \mathrm{Ge}_{2.2-2.6}$ the $p$-element atoms form empty square pyramids, which can be interpreted as arachno-clusters of the Wade type. The interatomic distances within the pyramids $\left(\delta_{M 1-M 3}=2.633(19) \AA, \delta_{M 1-M 2}=2.653(18)\right.$, $\delta_{M 4-M 2}=2.72(2) \AA, \delta_{M 4-M 3}=2.77(4), \delta_{M 4-M 1}=2.872(19) \AA$ in $\mathrm{Dy}_{3} \mathrm{Ga}_{3.5} \mathrm{Ge}_{1.5} ; \delta_{M 1-M 3}=2.664(11) \AA$, $\delta_{M 1-M 2}=2.668(8), \delta_{M 2-M 3}=2.762(12) \AA$ in $\left.\mathrm{Dy}_{3} \mathrm{Ga}_{2.4} \mathrm{Ge}_{2.6}\right)$ are the shortest distances in the structures.

The structure types $\mathrm{Tm}_{3} \mathrm{Ga}_{5}$ and $\mathrm{Pu}_{3} \mathrm{Pd}_{5}$ belong to the family of deformation variants of the structure type $\mathrm{Rh}_{5} \mathrm{Ge}_{3}$, which is characterized by interconnected infinite columns of filled trigonal prisms forming a three-dimensional network with large deformed hexagonal channels.

Keywords: dysprosium, gallium, germanium, X-ray powder diffraction, crystal structure.

Стаття надійшла до редколегії 01.11.2018

Прийнята до друку 23.01.2019 